\title{
The emerging role of social media platforms in advanced practice provider recruitment: One institution's experience
}

\author{
Ryan Krasnosky*, Jordan Rodriguez, Michelle Roy, Angelo P. Giardino
}

Texas Children's Hospital, United States

Received: December 17, 2018

DOI: $10.5430 /$ jha.v8n4p19
Accepted: March 28, 2019

Online Published: June 3, 2019

URL: https://doi.org/10.5430/jha.v8n4p19

\begin{abstract}
Social media is having a major impact on how today's society communicates with one another, receives information regarding current events, and professionally networking. With this rapid increase, this project sought to investigate the primary resources that Advanced Practice Providers (APPs) at Texas Children's Hospital used to find their current job and to determine what resources they would utilize for future positions. In the rapid increase of social media platforms and number of social media users, the recruiting needs may be changing drastically, specifically for job seekers in healthcare. As APPs search for employment, the avenues of seeking and applying for positions differ than they did when social media was not on the rise. This article discusses the progressive needs in the constantly evolving healthcare community in regards to recruiting and how, specifically, the APPs at Texas Children's Hospital (TCH) searched and applied for their position.
\end{abstract}

Key Words: Social media, Advanced Practice Providers, Recruitment

\section{INTRODUCTION}

History has taught us that the way information was spread amongst people many years ago was through hand delivered letters and printed newspapers. The delay in getting the printed updates to a recipient could cause for information to be outdated at the time of delivery. As you can imagine, receiving information that is not current is not an efficient nor effective way to share updates with people all across the world. In today's society as each generation develops, the needs and frequency of sharing data and information in a timely fashion is evolving as well. The millennial generation is the demographic cohort that is generally regarded to be composed of those individuals born between 1980 and 2000. They are the first to grow up in an environment where information is widely available by internet, TV and other electronic media. ${ }^{[1]}$ The progressive needs of electronic media usage can be directly correlated to the needs when finding employment, especially within the healthcare community. The world of healthcare is constantly evolving, including the way it recruits providers and employees. In able to recruit the most competitive candidates in this new world full of vast access to electronic media, employers are thinking of innovative platforms to do so, such as the use of social media.

Social media is defined as an internet-based tool that allows individuals to communicate with one another, share information or ideas, and collaborate with peers in real-time. ${ }^{[2]}$ In today's society, social media provides a variety of resources for its users. Resources can include, but are not limited to: all types of information sharing, emergency broadcasts dur-

*Correspondence: Ryan Krasnosky; Email: rkkrasno@texaschildrens.org; Address: Texas Children’s Hospital, United States. 
ing natural disasters, access to free (but often questionable) medical information online, ${ }^{[3]}$ and more recently, seeking employment opportunities. In addition to these uses, social media has been used as a platform for professional networking, that includes discussions for standard patient care as well as patient education amongst the healthcare community. ${ }^{[2]}$ With its creation to wide spread accessibility social media has grown in popularity in recent times. There has been an increase from $8 \%$ of U.S. adults using social media in 2005 to $72 \%$ in $2014 .{ }^{[2]}$ Cooper and Polonec (2012) showed in 2011 that $87 \%$ of U.S. physicians used social networking site for personal purposes and $67 \%$ used social networking sites for professional purposes. ${ }^{[4]}$ Given this trend Texas Children's Hospital (TCH) wanted to assess the effects social media might have on the recruitment process of Advanced Practice Providers (APPs).

To evaluate the evolving age of recruitment, APPs at TCH were surveyed to assess the trends of the current recruitment process. This paper outlines APP demographics at TCH, the tools used to find current employment and what platforms would be potentially utilized in the future for staffing.

\section{Methods}

At the time of this study, TCH employed 458 APPs and each was sent a questionnaire to evaluate modes used to find current employment and future resources that would be utilized to find employment. The survey was conducted via

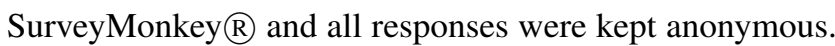
The data was compiled and analyzed to find some common trends in social media recruiting.

\section{RESUlts}

One hundred fifty three APPs within the institution completed an online questionnaire for a response rate of $33 \%$.
The online questionnaire inquired about how they found their current job and what resources they would use to search for future employment. APPs across multiple services and subspecialties at TCH were surveyed to assess demographics of their job history and what tactics were utilized in their job search. A majority of the providers surveyed were female (see Figure 1). Providers were found to have a variety of experience. Half of the pool of providers surveyed were found to have previous experience as a physician assistant (PA) or nurse practitioner (NP) while the remaining surveyed were new graduates entering the workforce (see Figure 2). Of the providers that had previous experience as a PA or NP the number of years of experience were evenly dispersed from at least one year $(21.6 \%)$ to greater than ten years of experience (18.9\%) (see Figure 3). Regardless of years of experience providers were asked what the primary source was for finding their current job. Most providers stated networking (word of mouth) was the primary platform used to find their current employment (37\%). Of the providers surveyed, $49.67 \%$ were employed at another hospital or institution prior to their current role (see Figure 4). Social media platforms such as Facebook, online-blogs, Instagram, and LinkedIn were rarely utilized (see Figure 5). This trend is likely due to the newness of social media and its effect on employment marketing. Interestingly, when asked what resources would providers use to search for future employment most continued to utilize networking as their primary resource (73\%). However, newer platforms such as social media were now entertained as a possible resource. Platforms such as Facebook (15.7\%), online-blogs (5.2\%), Instagram (3.3\%), and LinkedIn (34\%) were listed as possible means for assisting with future job searches (see Figure 6). These numbers could represent a new trend towards a more socially driven search.

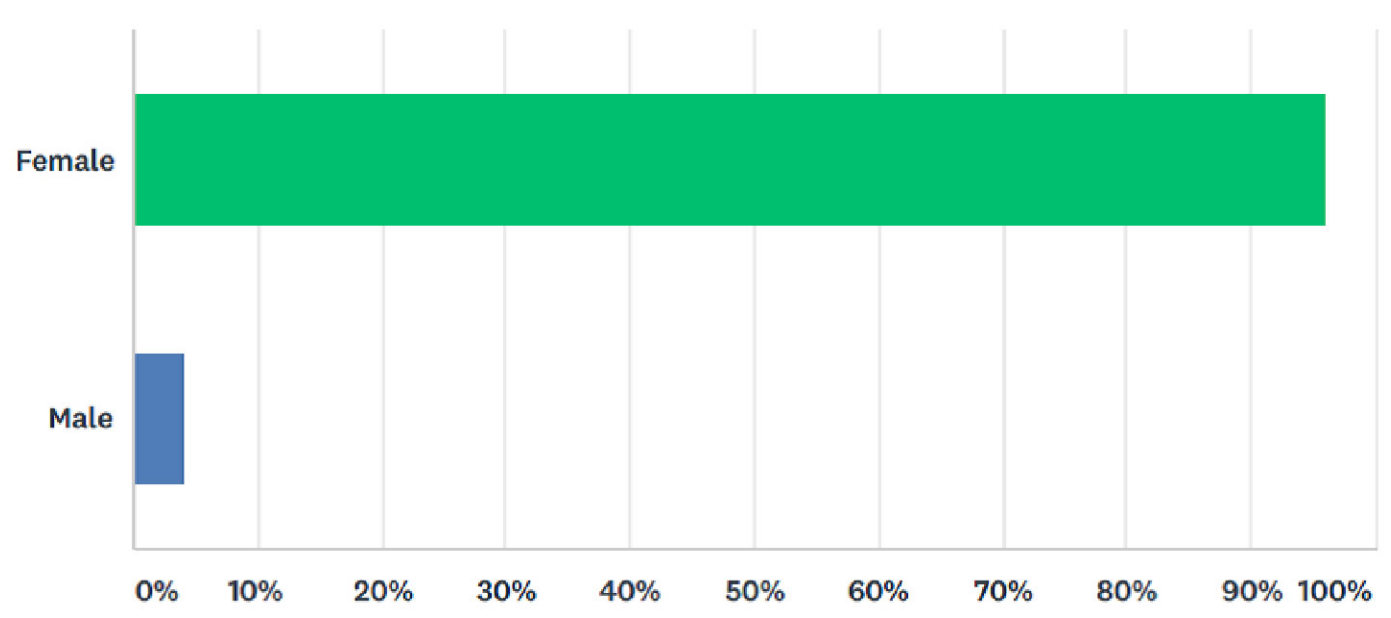

Figure 1. A majority of the respondants of the APPs surveyed at TCH were female (96\%) 


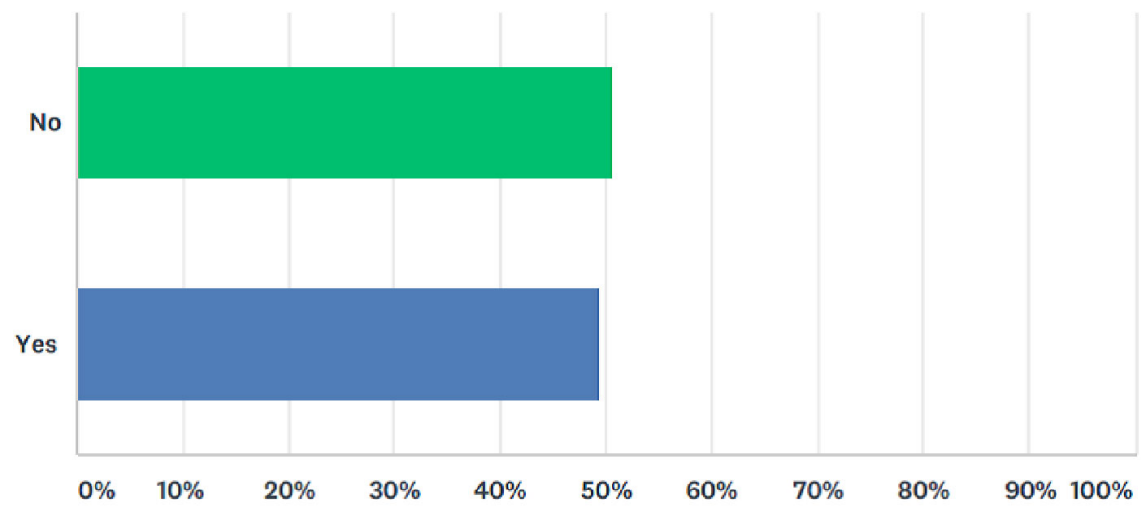

Figure 2. Of the APPs surveyed at TCH approximately half had been previously employed as a Physician Assistnat or Nurse Practitioner (49\%). Whereas, the other half were new graduates (50\%)

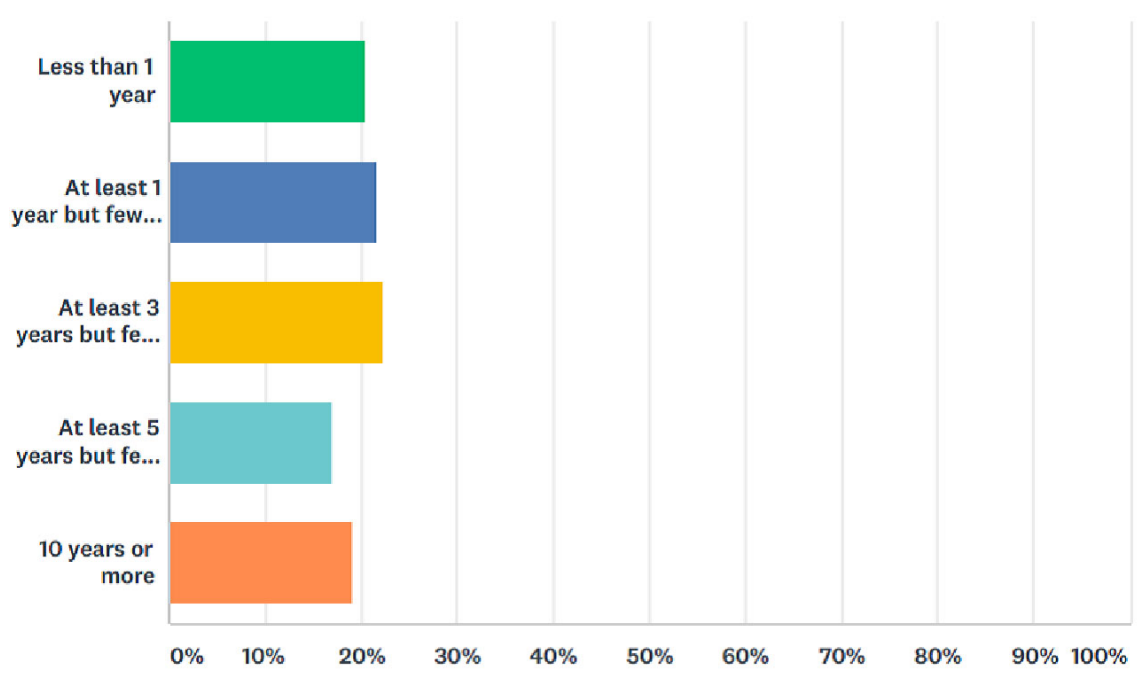

Figure 3. APPs surveyed had a variety of years of experience and were evenly distritbuted from less than one year at current position (20\%) to greater than 10 years at current position $(18.9 \%)$

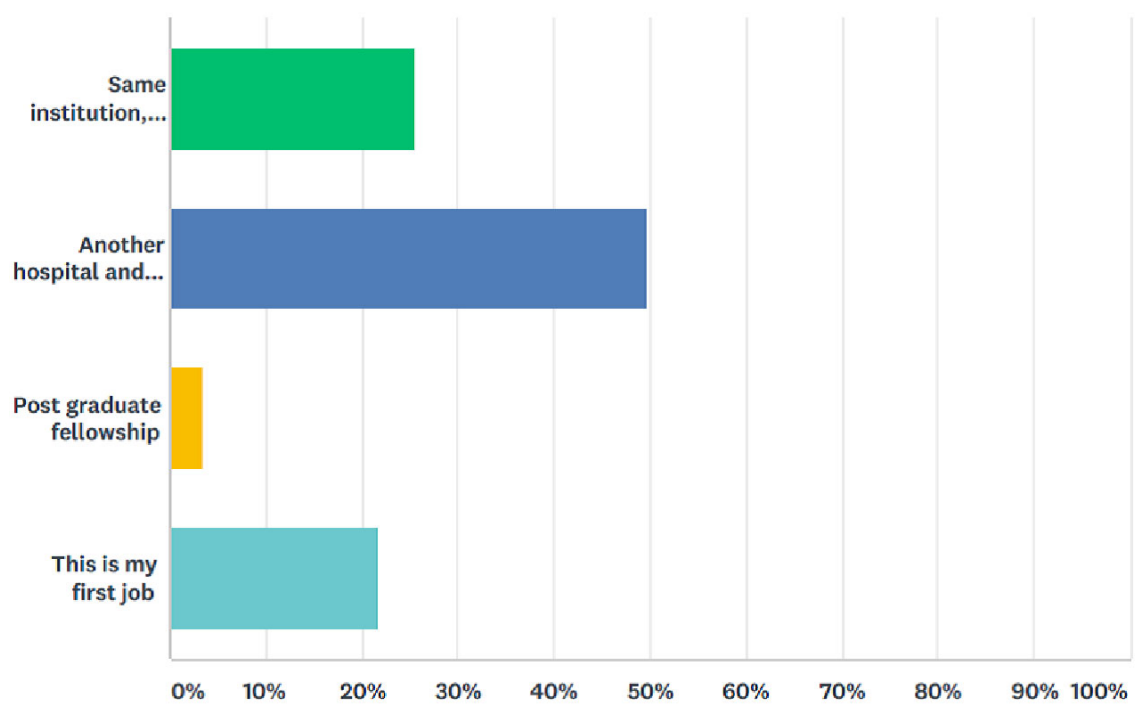

Figure 4. APPs surveyed came from a variety of backgrounds including: being employed at other institutions (49.6\%), coming from a post graduate fellowship (3.2\%), and being a new graduate $(21.6 \%)$ 


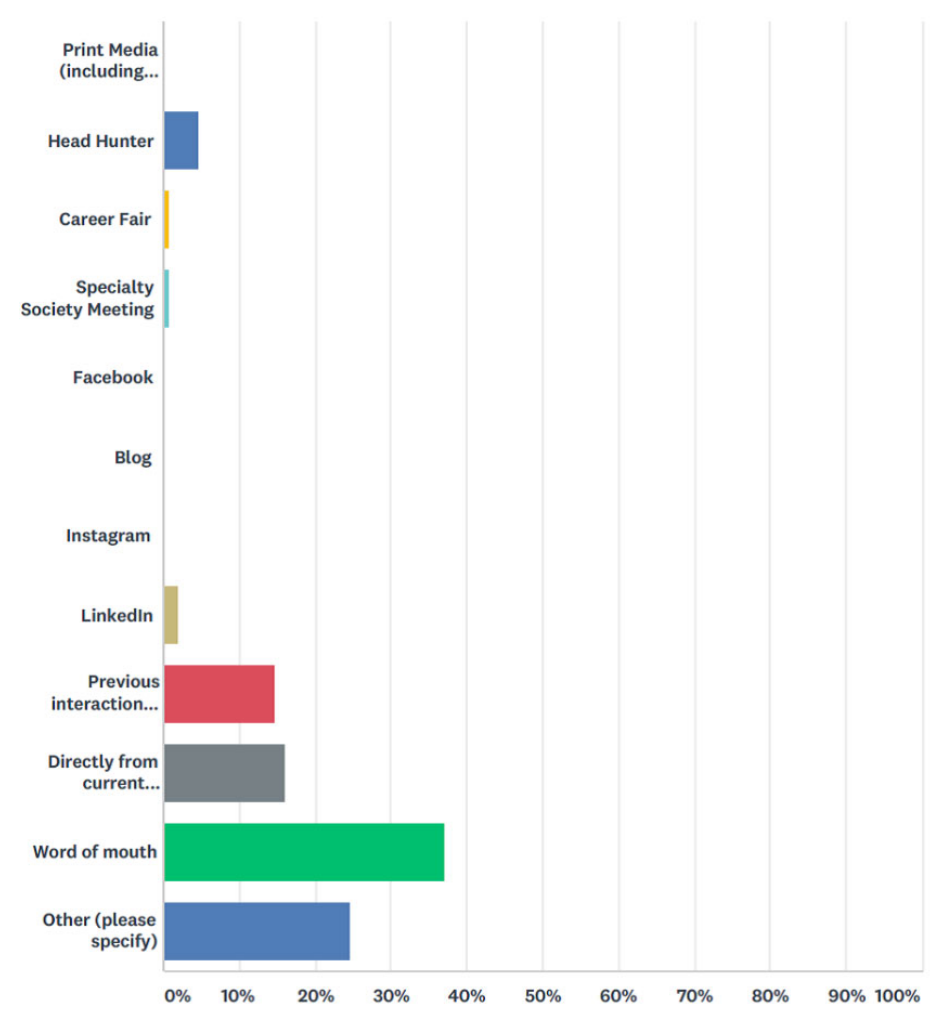

Figure 5. A majority of APPs surveyed described finding their current job by word of mouth/networking (37\%)

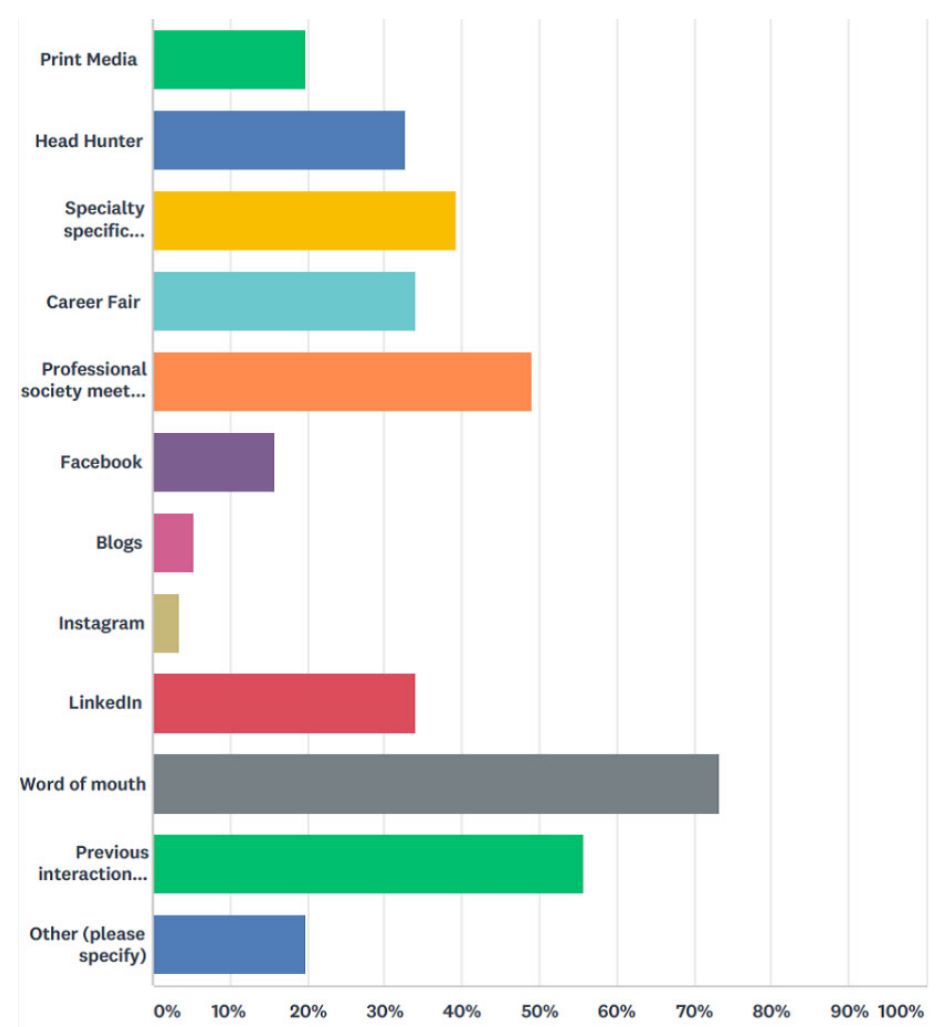

Figure 6. APPs surveyed would utilize a variety of platforms to search for a new position. However, networking would still remain the primary resource utilized $(73 \%)$.

Trends show newer platforms such as social media as being resources entertained, but still not the primary source. Social media platforms include: Facebook (15.7\%), online-blogs (5.2\%), Instagram (3.3\%), and LinkedIn (34\%) 


\section{Conclusion}

Social media is having a major impact on how today's society communicates with one another, receives information regarding current events, and professionally networking. In this paper that sought to investigate the primary resources used by APPs to find their current job and what resources they would utilize for future positions a trend was identified showing that slightly over a third of providers use social media to aid in their search for employment. Social media platforms such as Instagram (3.3\%), Facebook (15.7\%), and LinkedIn (33.9\%) were identified as potential tools for recruitment. While networking (word of mouth) remained the highest reported source used to find current positions a trend was noticed that a small change has occurred where a small portion of the population would utilize social media for future searches. This trend may correlate how our society is evolving to one that utilizes such platforms although further investigation must be performed. As we progress through the second decade of the new millennia and travel along the new digital highway, those who recruit APPs will increasingly need to include this new platform into any comprehensive recruitment strategy.

\section{CONFlicts OF InTEREST Disclosure}

The authors declare they have no conflicts of interest.

\section{REFERENCES}

[1] Lloyd T, Shaffer ML, Christy S, et al. Health Knowledge Among the Millennial Generation. 2013. Available from: https://www.ncbi .nlm.nih.gov/pmc/articles/PMC4140324/\#, 1, 38-41

[2] Ventola CL. Social media and health care professionals: benefits, risks, and best practices. Pharmacy and Therapeutics. 2014; 39(7): 491-520.
[3] Cooper CP, Gelb CA, Rim SH, et al. Physicians who use social media and other internet-based communication technologies. J Am Med Inform Assoc. 2012; 19(6): 960-4. PMid:22634078. https://doi.org/10.1136/amiajnl-2011-000628

[4] Von muhlen M, Ohno-machado L. Reviewing social media use by clinicians. J Am Med Inform Assoc. 2012; 19(5): 777 81. PMid:22759618. https://doi.org/10.1136/amiajnl-201 2-000990 